\title{
The Influence of Corrosion on the Mechanical Behavior of AISI 316L Stainless Steel Welds
}

\author{
Murat TÜRKAN*,**, Özler KARAKAŞ* \\ *Pamukkale University, Kınıkl,,20070,Denizli,Turkey,E-mail: okarakas@pau.edu.tr \\ **Izmir University of Economics, Balçova, 35330, Izmir, Turkey, E-mail: murat.turkan@ieu.edu.tr \\ cross $^{\text {ref }}$ http://dx.doi.org/10.5755/j01.mech.25.2.21551
}

\section{Introduction}

Stainless steel, classified under five groups as martensitic, ferritic, austenitic, precipitation hardened and double phase, are widely used in industries, such as the food industry, chemistry, power engineering, medical applications, high or subzero temperature applications, petroleum, petrochemical and textile, transport and architectural applications.

Stainless steels do not greatly differ from other steels in mechanical properties. Despite the high cost, stainless steels are in widespread use due to their high corrosion resistance. However, stainless steels are subject to corrosion as other steels by the constant aggressive effect of the environment or due to chemical and physical defects.

Austenitic stainless steels have by far the greatest share in total stainless steel production. The annual amount of stainless steel produced in the world is about 1400 million tons. More than half of this amount is austenitic stainless steels [1]. Austenitic stainless steels offer a very suitable combination in terms of mechanical properties, corrosion resistance and formability. 316L austenitic stainless steel is given preference as a structural material among other austenitic grades, due to fine mechanical properties and higher corrosion resistance at various temperatures [2].

Good welding appearance and high quality welds are obtained by TIG welding methods. Therefore, it is one of the most frequently used welding methods in many industrial fields $[3,4]$. In this welding process, welding is performed using an arc generated between a nonconsumable tungsten electrode and the workpiece. Inert or mixture gases are used to protect the weld area [5]. Compared to other welding methods, the penetration power in this method is relatively less [3, 4]. Therefore filler metal may be used depending on the thickness of the workpiece.

Austenitic stainless steels can be joined with various welding methods, if appropriate. Only a small number of metallurgical events in the welding zone and / or discontinuities due to welding defects can occur during welding operations. Such conditions negatively affect the

corrosion resistance of the austenitic stainless steel.

In the majority of corrosion events, the fracture or surface damage are the result of the high stresses that occur under load, and consequently, the fatigue strengths of parts subjected to dynamic stresses are reduced considerably [6].

Hence, determining together the corrosion and mechanical behaviours of welded $316 \mathrm{~L}$ grade stainless steels is of significant importance for safe engineering constructions.

\section{Experimental detail}

In the experimental study, 4 mm-thick AISI $316 \mathrm{~L}$ austenitic stainless steel flat products were used as a base material. Representations of base materials in various standards are shown in Table 1. In addition, chemical composition of the stainless steel used as a base material in the experiments is shown in Table 2.

The TIG welding process was done both with and without filler metal to investigate the effects of the addition of filler metal to the TIG welding methods. The filler metal were composed of ER316L SS filler rod with diameter of $2.4 \mathrm{~mm}$. The chemical composition of the TIG welding filler metal is shown in Table 3 .

For joints with filler metal, $60^{\circ}$ double V-grooved plates were used, and for joints without filler metal, square butt grooves. The welding was performed as single-run and double-sided for both joints. Joints with filler metal had $2 \mathrm{~mm}$ root gaps, while joints without filler metal were constructed without root gaps. $2 \%$ thorium alloy tungsten electrode with direct current power supply was used. Diameter of tungsten electrode is $2.4 \mathrm{~mm}$. The electrode was connected to the anode to provide greater penetration. Arc length and nozzle diameter were $2 \mathrm{~mm}$ and $9.5 \mathrm{~mm}$, respectively. The welding direction was the same as the rolling direction of the plate. Pure argon was used as the shielding gas, and was also protected by argon behind the weld in joints without filler metal. The other welding parameters are shown in Table 4.

Table 1

Presentation of the base material in the AISI and EN Standards

\begin{tabular}{|c|c|c|}
\hline AISI & EN 10088 Material No & EN 10088 Designation \\
\hline 316L & 1.4404 & X2CrNiMo17-12-2 \\
\hline
\end{tabular}

Table 2

Chemical composition of the stainless steels used in the experiments (\% weight)

\begin{tabular}{|c|c|c|c|c|c|c|c|c|c|}
\hline Base Material [AISI] & $\mathrm{C}$ & $\mathrm{Si}$ & $\mathrm{Mn}$ & $\mathrm{P}$ & $\mathrm{S}$ & $\mathrm{Cr}$ & $\mathrm{Ni}$ & $\mathrm{N}$ & $\mathrm{Mo}$ \\
\hline 316L & 0.025 & 0.39 & 0.88 & 0.033 & 0.001 & 17.05 & 10.05 & 0.059 & 2.03 \\
\hline
\end{tabular}


Table 3

Chemical composition of filler metal used in TIG welding (\% weight)

\begin{tabular}{|c|c|c|c|c|c|c|c|c|}
\hline \multicolumn{2}{|c|}{ Filler Metal } & \multirow{2}{*}{$\mathrm{C}$} & \multirow{2}{*}{$\mathrm{Si}$} & \multirow{2}{*}{$\mathrm{Mn}$} & \multirow{2}{*}{$\mathrm{Cr}$} & \multirow{2}{*}{$\mathrm{Ni}$} & \multirow{2}{*}{ Mo } & \multirow{2}{*}{$\mathrm{P}+\mathrm{S}$} \\
\hline AWS A5.9 & EN ISO 14343 & & & & & & & \\
\hline ER316L & W $19123 \mathrm{~L}$ & $<0.03$ & 0.45 & 1.70 & 18 & 12 & 2.50 & $<0.060$ \\
\hline
\end{tabular}

Welding parameters

Table 4

\begin{tabular}{|c|c|c|c|}
\hline Specimen & Current, $\mathrm{A}$ & Welding speed, $\mathrm{mm} / \mathrm{min}$ & Gas flow, $\mathrm{l} / \mathrm{min}$ \\
\hline Joints with filler metal & 110 & 1.6 & 10 \\
\hline Joints without filler metal & 180 & 4.9 & 10 \\
\hline
\end{tabular}

\section{Results and discussion}

Cross-section macro-structure photographs of weld metal are shown in Figure 1. It is clear that there is no crack, porosity, or insufficient penetration for both joints. It is seen that the welding transition zone is wider and smoother in joints without filler metal. In this case, the relatively high current value and the low welding speed have a great effect. Due to the high heat input, some distortions are observed in joints with filler metal. It can be considered that both are good joints.

Cross-section micro-structure photographs of weld zone are shown in the Figs 2 and 3. Figs. 2 and 3 clearly show the austenitic structure as the base material. In the heat affected zones (HAZ) there has been a transition to the base material with fine dendritic $\delta$-ferrite. In Fig. 2, c. and 3, c., the weld metals (WM) can be clearly identified. In WM, $\delta$ ferrite was formed in the austenite matrix for both joints. The quantity of $\delta$-ferrite in samples jointed with filler metal is slightly higher. The quantity of $\delta$-ferrite is highly dependent on the chemical properties of the filler material and the rate of cooling. A certain quantity of $\delta$-ferrite is
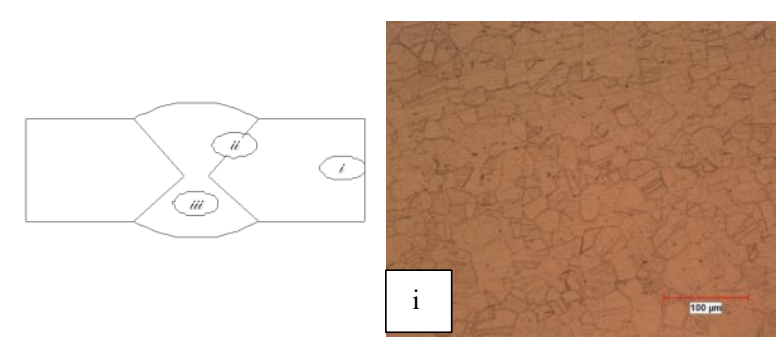

a

$\mathrm{b}$

useful for the welded austenitic stainless steels. 3-7 Vol.\% of the $\delta$-ferrite formed in austenite matrix acts to inhibit hot cracks during solidification $[7,8]$. In addition, it is known that $\delta$-ferrite contains higher $\mathrm{Cr}$ than the austenitic structure. This results in a higher corrosion resistance when $\delta$-ferrite is compared to the austenitic phase. Besides this, the existence of two phases with distinct corrosion resistances may lead to the formation of active-passive regions and corrosion [9].

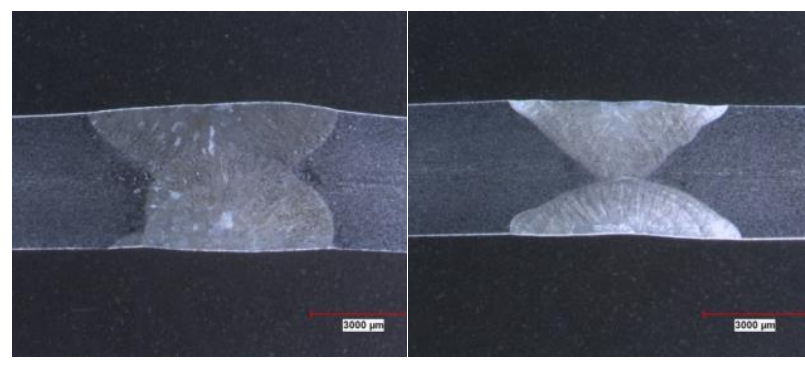

a

$\mathrm{b}$

Fig. 1 Macrostructure of welded joints: (a) without filler metal (b) with filler metal

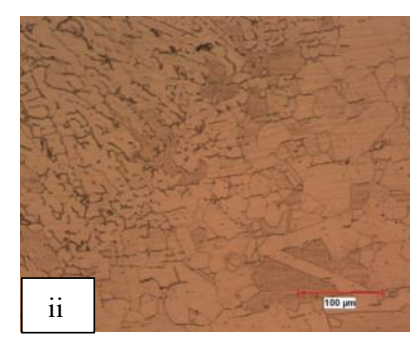

c

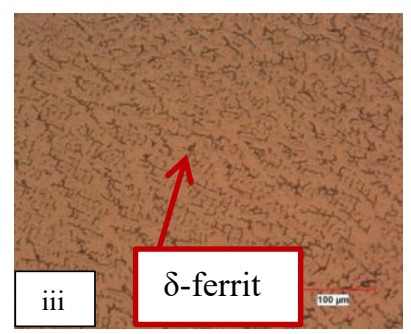

d

Fig. 2 Microstructure of joints without filler metal (a) Illustrated regions (i,ii,iii) in (b), (c), (d); (b) BM (c) HAZ (d) WM

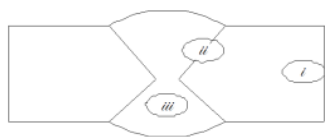

a

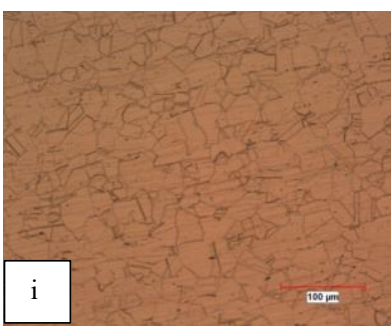

$\mathrm{b}$

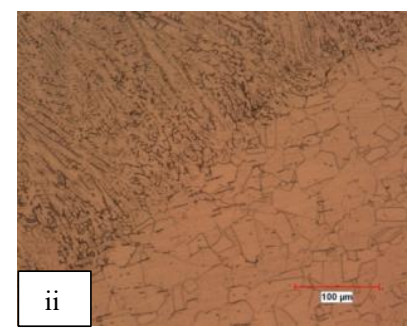

C

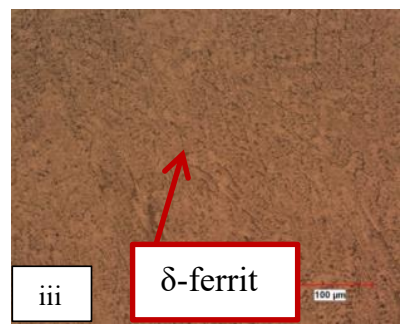

d

Fig. 3 Microstructure of joints with filler metal (a) Illustrated regions (i, ii, iii) in (b), (c), (d); (b) BM (c) HAZ (d) M

The micro hardness values of the cross sections of the welded joints are illustrated in Fig. 4. In the joints with filler metal, some higher degrees of hardness were measured in the weld zone because of the chemical properties of the filler material, and also the faster cooling rate. Very high hardness differences were not found between the HAZ and the BM, due to the austenitic structure of the base material. Similarly, no important change in hardness values between $\mathrm{HAZ}$ and BM were observed in previous studies [10-12].

Salt spray tests were carried out in conformity with EN ISO 9227 standard, "Corrosion test in artificial environments". Experiments were conducted for 24-96- 
240-480-720-1000 hours as recommended in the relevant standard. The saline solution, obtained by dissolving $5 \mathrm{~g}$ of $\mathrm{NaCl}$ in $95 \mathrm{ml}$ of water, was used as a corrosive environment. In the solution, pure water and a chemical analysis certified special salt were used. The temperature of the cabin was kept constant at $35^{\circ} \mathrm{C}$. The $\mathrm{pH}$ of the solution collected in the cabin was checked at regular intervals and adjusted to ensure it remained between 6.5 and 7.2 when necessary. The CW Equipment salt spray cabinet used in the experiments is shown in Fig. 5.

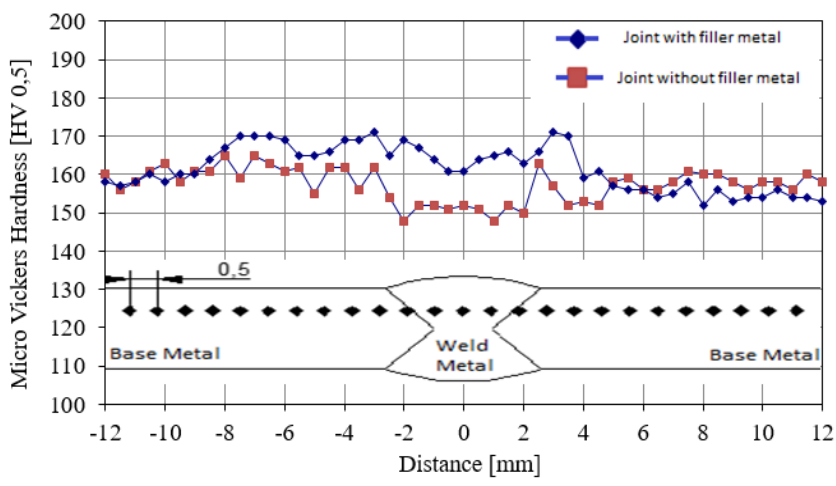

Fig. 4 Micro hardness values of the cross-sections of the welded joints

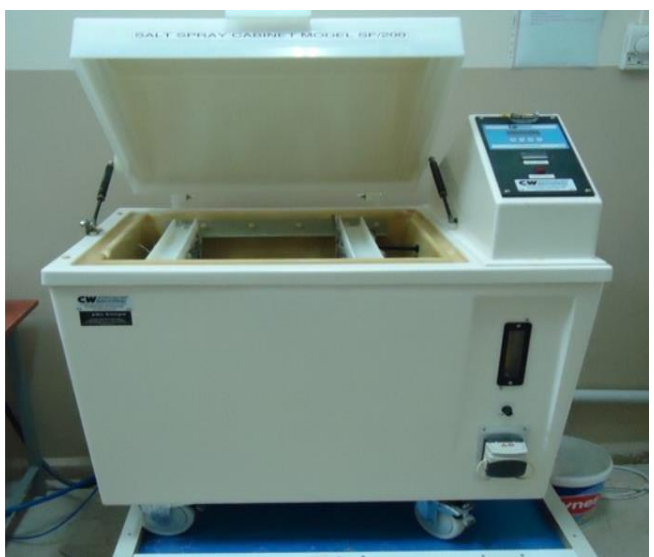

Fig. 5 Salt spraying cabinet used in experiments

After the welding process, surface heat treatment stains can adversely affect the corrosion behaviour of stainless steel. For this reason, after the welding process, a welding stain cleaning paste was applied to the region under heat. Then samples were rinsed with plenty of water to remove heat treatment stains. The burrs of the tensile specimens that were to be exposed to salt spray were grinded. After the surfaces of the samples were cleaned with ethyl alcohol, the salt spray experiments began. The layout of the specimens in the salt spray cabinet is shown in Fig. 6.

Photographs of the samples after 1000 hours of salt spray are shown in Fig. 7. No corrosion product was observed. After salt spray experiments, the samples were washed with plenty of water. Then surfaces were cleaned with ethyl alcohol, and mass loss calculation was made. No mass loss was found, due to the stability of the passive layer in the weld zone.

Tensile tests were carried out following salt spray tests. Three tensile tests were performed for each salt spray test period. The average of the results of these three tensile tests was taken for each experimental period. In the tensile test, most of the fractures taken place in the base metal.
Samples broken from weld metal were not evaluated. The breakdown of the base metal is due to higher strength value of the weld metal compared to the base metal and there are no welding defects. The dimensions of the tensile test samples are shown in Fig. 8. The mechanical properties of welded samples are illustrated in Table 5 . It is seen that the ultimate tensile strength and yield strength values are the same. However, the elongation (\%) values were about $20 \%$ higher in the joints without filler metal, because the weld metal exhibits more ductile behaviour. Also there was no change in the modulus of elasticity in both joints. In the experiments conducted for 304L stainless steel, the same tendency was observed [12].

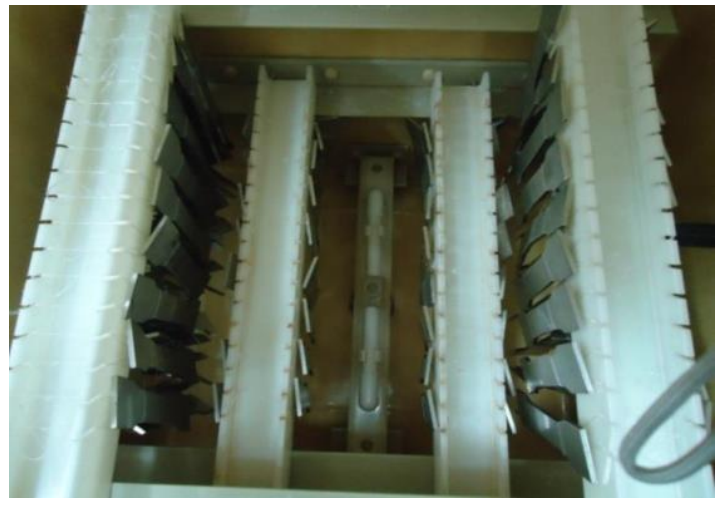

Fig. 6 The layout of the specimens in the salt spray cabinet

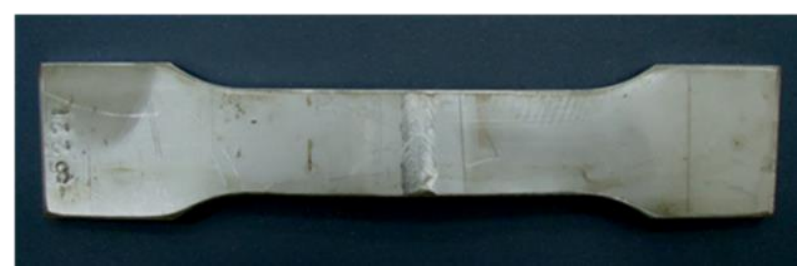

a

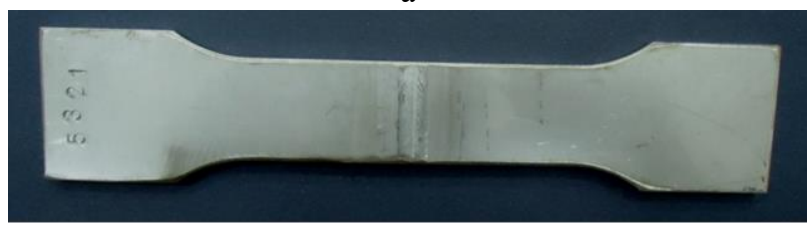

b

Fig. 7 After the 1000 hours salt spray test, photographs of the specimens:(a) without filler metal, (b) with filler metal

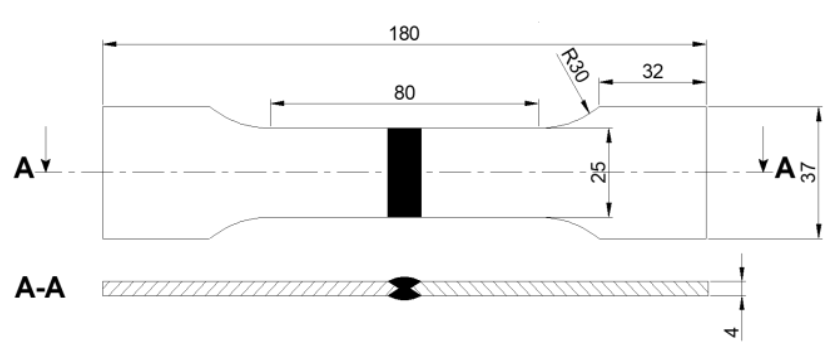

Fig. 8 Dimensions of the tensile test sample

Table 5

Tensile properties of welded joints

\begin{tabular}{|c|c|c|c|}
\hline Specimen & $\begin{array}{c}\text { Ultimate tensile } \\
\text { strength, MPa }\end{array}$ & $\begin{array}{c}\text { Yield } \\
\text { strength, MPa }\end{array}$ & $\begin{array}{c}\text { Elongation, } \\
\%\end{array}$ \\
\hline $\begin{array}{c}\text { Joints without } \\
\text { filler metal }\end{array}$ & 581 & 333 & 61 \\
\hline $\begin{array}{c}\text { Joints with filler } \\
\text { metal }\end{array}$ & 576 & 328 & 43 \\
\hline
\end{tabular}


The mechanical properties of the welded joints according to the salt spray test times are shown in Figs. 9, 10 and 11. It is clearly apparent that there are no changes in mechanical properties according to salt spray time.

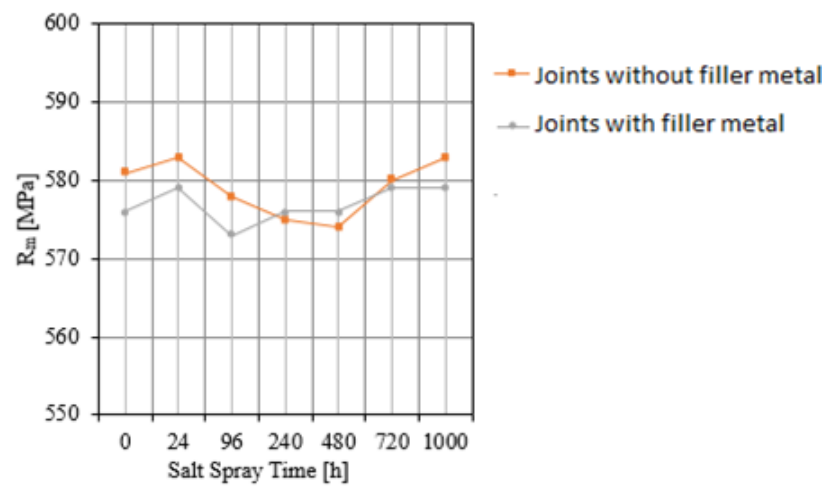

Fig. 9. Tensile strength according to salt spraying time.

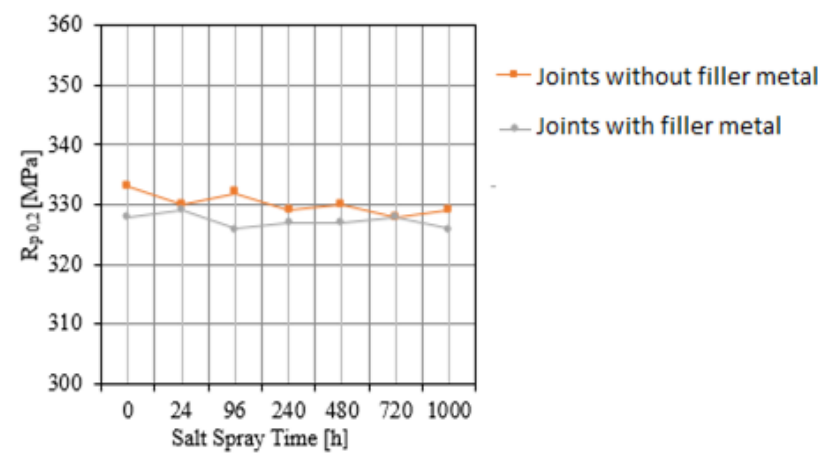

Fig. 10 Yield strength according to salt spraying time

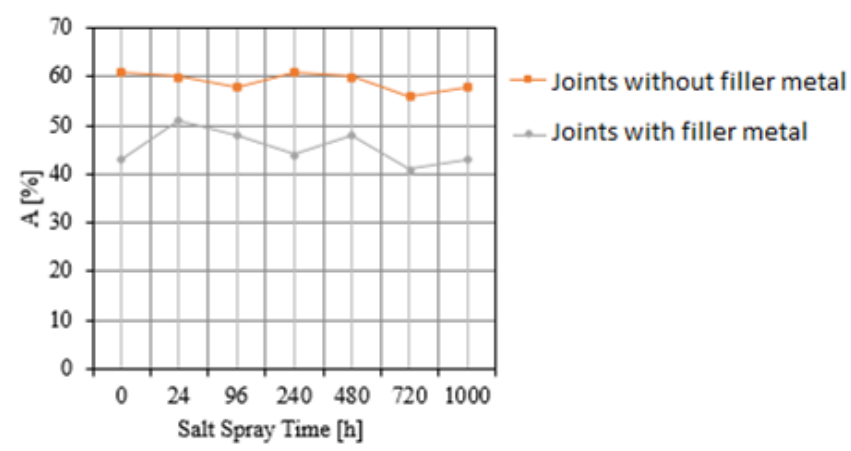

Fig. 11 Elongation (\%) according to salt spraying time

\section{Conclusions}

1. AISI 316L stainless steels can be successfully joined with TIG welding method, both with and without filler metal. Similar mechanic features obtained from many samples show that the quality of the weld metal does not change along the seam.

2. $\delta$-ferrite is formed in the austenitic matrix in the weld metal for both joints. The amount of $\delta$-ferrite in the joints with filler metal is slightly higher due to chemical composition of filler metal and cooling rate

3. Ultimate tensile strength and yield strength values are the same for both joints. However, joints without filler metal exhibited about $20 \%$ higher elongation values due to the relatively higher ductility of the weld metal.

4. There was no change in the mechanical properties of the samples depending on the duration of the salt spray.

\section{Acknowledgement}

The authors are grateful for financial support from the Pamukkale University Scientific Research Projects Coordination Unit under grant No: 2011FBE083.

\section{References}

1. Bermejo, M. A. V.; Debroy, T.; Hurtig, K.; Karlsson, L.; Svensson, L. E. 2015. Towards a map of solidification cracking risk in laser welding of austenitic stainless steels, Physics Procedia 78: 230-239.

https://doi.org/10.1016/j.phpro.2015.11.033.

2. Samanta, S. K.; Mitra, S. K.; Pal, T. K. 2006. Effect of rare earth elements on microstructure and oxidation behavior in TIG weldments of AISI 316L stainless steel, Materials Science and Engineering A 430: 242-247. https://doi.org/10.1016/j.msea.2006.05.063.

3. Fujii, H.; Sato, T.; Lu, S.; Nogi, K. 2008. Development of an advanced A-TIG (AA-TIG) welding method by control of Marangoni convection, Materials Science and Engineering A 495: 296-303. https://doi.org/10.1016/j.msea.2007.10.116.

4. Wu, B.; Wu, Wang, B.; Zhao, X.; Peng, H. 2018. Effect of active fluxes on thermophysical properties of 309L stainless-steel welds, Journal of Materials Processing Technology 255: 212-218. https://doi.org/10.1016/j.jmatprotec.2017.12.018.

5. Modenesi, P. J.; Apolinario, E. R.; Pereira, I. M. 2000. TIG welding with single-component fluxes, Journal of Materials Processing Technology 99: 260265. https://doi.org/10.1016/S0924-0136(99)00435-5.

6. Türkan, M.; Karakaş, Ö. 2017. The effect of welding defects to the tensile behavior in corrosive environment of AISI 304L stainless steel joined with shielded metal electrode, Journal of Achievements in Materials and Manufacturing Engineering 85/1: 26-30. https://doi.org/10.5604/01.3001.0010.7986.

7. Dutt, B. S.; Sasikala, G.; Shanthi, G.; Venugopal, S.; Babu, M. N.; Parida, P. K.; Bhaduri, A. K. 2011. Mechanical behaviour of SS 316 (N) weld after long term exposure to service temperatures, Procedia Engineering 10: 2725-2730.

https://doi.org/10.1016/j.proeng.2011.04.454.

8. David, S. A.; Vitek, J. M.; Alexander, D. J. 1996. Embrittlement of austenitic stainless steel welds, Journal of Nondestructive Evaluation 15: 129-136.

9. Silva, C. C.; Miranda, H. C. D.; Sant'ana, H. B. D.; Farias, J. P. 2009. Microstructure, hardness and petroleum corrosion evaluation of $316 \mathrm{~L} / \mathrm{AWS}$ E309MoL-16 weld metal, Materials Characterization 60: $346-352$.

https://doi.org/10.1016/j.matchar.2008.09.017.

10. Gülenç, B.; Develi, K.; Kahraman, N., Durgutlu, A. 2005. Experimental study of the effect of hydrogen in argon as a shielding gas in MIG welding of austenitic stainless steel, International Journal of Hydrogen Energy 30: $1475-1481$.

https://doi.org/10.1016/j.ijhydene.2004.12.012.

11. Durgutlu, A. 2004. Experimental investigation of the effect of hydrogen in argon as a shielding gas on TIG welding of austenitic stainless steel, Materials and Design 25: 19-23. 
https://doi.org/10.1016/j.matdes.2003.07.004.

12. Türkan, M.; Karakaş, Ö. 2017. Corrosion and mechanical behaviour of TIG-welded AISI 304L stainless steel, Journal of the Balkan Tribological Association 23(4): 653-663.

\section{Turkan, Ö. Karakaş}

\section{THE INFLUENCE OF CORROSION ON THE} MECHANICAL BEHAVIOR OF AISI 316L STAINLESS STEEL WELDS

\section{S u m m a r y}

Stainless steels are widely used because they have high corrosion resistance. However, they can also suffer corrosion due to the constant aggressive effect of the environment or due to chemical and physical malfunctions. It is of great importance to determine the behavior of welded austenitic stainless steels in corrosive environments for safer construction. For this reason, in this study, the corrosion and mechanical behavior of welded austenitic stainless steels exposed to salt spray was investigated. In the first stage, commercially available AISI $316 \mathrm{~L}$ austenitic stainless steel materials with $4 \mathrm{~mm}$ thickness were joined with the TIG welding method, both with and without filler metal. To specify the structure of the weld zone, the micromacrostructure and micro hardness values of the welded samples were examined before the salt spray experiments. The salt spray test was performed in compliance with the EN ISO 9227 "Corrosion test in artificial environments" standard, in which the tensile samples of welded AISI $316 \mathrm{~L}$ materials were subjected to salt spray test up to 1000 hours. Tensile tests were carried out following salt spray tests.

Keywords: TIG welding method, corrosion, filler metal, AISI 316L austenitic stainless steel.

Received August 30, 2018

Accepted April 25, 2019 